\title{
NECROPSIA COSMÉTICA EM AVES
}

\author{
Guilherme Augusto Marietto Gonçalves, Breno Souza Salgado \\ 1 Universidade Estadual Paulista - UNESP \\ Endereço para correspondência: Breno Souza Salgado: brenosalgado@globo.com
}

RESUMO: A necropsia é um exame post-mortem criterioso que auxilia no diagnóstico clínico e que consiste na análise externa e interna das cavidades corporais e órgãos de um cadáver, no intuito de elucidar a causa da morte ou verificar a extensão e natureza das lesões provocadas pelas doenças. Considerando o vínculo existente entre proprietários e animais de estimação, muitos Médicos Veterinários visualizam a necropsia como uma tarefa difícil de ser realizada. Este contexto vem ganhando importante destaque na Medicina Veterinária de aves, uma vez que os proprietários de tais animais possuem tanto vínculo sentimental quanto econômico. Na Medicina Veterinária a necropsia é geralmente negligenciada, mesmo sendo uma prática muito importante tanto para o aprendizado do profissional quanto para a obtenção de um diagnóstico fidedigno de algumas doenças. Por essas razões, esse artigo objetiva descrever o método de realização da necropsia cosmética em aves, que mantém as características externas dos animais e aumenta a aceitação dos proprietários por não desfigurar o cadáver.

Palavras-chave: Necropsia cosmética, aves, vínculo homem-animal de estimação.

\section{AVIAN COSMETIC NECROPSY}

ABSTRACT: Necropsy is a post-mortem criterious exam that helps in clinical diagnosis and consists in external and internal analysis of body cavities and organs of a corpse in order to determine the cause of death or to verify the extension and the nature of lesions caused by diseases. Considering the bonds between owners and their pets many veterinarians seems to visualize necropsy as a difficult task. This fact has gained great importance in avian Veterinary Medicine since bird owners have both love and economic bonds. Necropsy in often neglected in Veterinary Medicine although being a very important practice for the professional learning and also for reaching a reliable diagnosis of certain diseases. For this reason, this article aims to describe the procedure for performing avian cosmetic necropsy, which keeps the external characteristics of animals and increases the acceptance of owners by not disfiguring the corpse.

Key Words: Cosmetic necropsy, birds, human-pet bonding. 


\section{INTRODUÇÃO}

A necropsia é uma parte importante da medicina aviária. Freqüentemente, sinais clínicos e achados de patologia clínica não são definitivamente explicados até 0 momento do exame post-mortem. A necropsia é muito mais do que satisfazer a curiosidade do proprietário, criador ou veterinário responsável, pois intenta prover informações importantes que podem ser utilizadas no diagnóstico e tratamento de casos futuros.

Para os proprietários de pássaros assumidos como animais de companhia, informações obtidas à necropsia podem aliviar alguma ou toda culpa associada à morte de seus animais possivelmente presente e certificar que eles fizeram tudo ao seu alcance para a recuperação desses. Em situações onde 0 proprietário manifeste insatisfação com o tratamento ou resolução do caso, é sábio permitir que a necropsia seja realizada por um ornitopatologista ou patologista veterinário com experiência em avaliação de aves, domésticas ou não.

O vínculo entre proprietários e seus animais tem evoluído a um ponto no qual os animais de companhia são considerados mais que isso, são tidos também como membros da família (Lorenz, 1997; Brown, 2004). Essa é uma particularidade principalmente para cães e gatos, que têm sido elevados a uma posição na sociedade onde suas principais funções são prover companhia, criar vínculo de amizade com seu proprietário e preencher o espaço deixado por pessoas próximas (Allen, 1995). Entretanto, muitos dos proprietários de aves têm se comportado de maneira semelhante, quer seja pelo valor econômico ou sentimental de seus animais. Sendo assim, nos casos de morte, o cadáver animal recebe igual respeito e a partir disso não é incomum encontrar proprietários que se opõem à realização de um exame post-mortem convencional em seus animais, podendo assim, dificultar um diagnóstico mais preciso.

A necropsia (do grego nekros: morte ou cadáver, e opsis: ação de ver ou examinar) é um exame criterioso externo e interno de um cadáver com a finalidade de definir a causa mortis. Entende-se por causa mortis as doenças, estados mórbidos e as lesões que ocasionaram a morte ou contribuíram para que ela ocorresse. Portanto, necropsia é o estudo da morte e tudo relacionado a ela, tendo como centro o cadáver e, como epicentro, descobrir a causa da morte (Silva \& Vargas, 2005).

A realização da necropsia é necessária para responder às questões clínicas, revelar informações que não foram previamente identificadas quando - paciente ainda estava vivo e direcionar para a tomada de decisões futuras (Hull et al., 2007). Acima de tudo, é uma ferramenta de aprendizado não só para o patologista como também para o clínico, permitindo que tais profissionais relacionem achados prévios com aqueles demonstrados pela necropsia, sendo assim um excelente meio de educação continuada (Silva \& Vargas, 2005; Burton \& Underwood, 2007).

Muitas vezes, os proprietários não se opõem ao propósito da necropsia em si, mas optam por não realizá-la devido aos procedimentos utilizados na técnica, que consiste no desmembramento do cadáver em várias partes corporais, retirando-se dele todos os órgãos e estruturas. Isso obviamente não é de interesse de muitos proprietários, os quais gostariam de fornecer um funeral, ou ainda temem que o cadáver seja manuseado de forma desrespeitosa. Este pensamento é similar ao que ocorre entre os seres humanos (Hull et al., 2007; Burton \& 
Underwood, 2007), tendo em vista a posição atual dos animais na sociedade.

Neste contexto, é necessário ter em mente a possibilidade de realização de uma necropsia cosmética (do grego kosmetikós: o que serve para ornamentar), utilizando procedimentos que limitam as ações que desfigurem o cadáver. Cabe lembrar que a necropsia não é um simples retalhamento ou um esquartejamento do animal, mas sim uma análise sistemática e científica de um cadáver que deve ser realizada com todo o respeito (Carvalho, 1942).

Sendo assim, o objetivo deste trabalho é fornecer um guia prático de execução da técnica de necropsia cosmética em aves bem como atentar sobre as vantagens e desvantagens na sua realização dentro da rotina médicaveterinária aviária.

\section{DESENVOLVIMENTO}

Para a execução da técnica e colheita de material deve-se analisar a história clínica e realizar uma avaliação externa rigorosa do animal, de maneira semelhante ao que é preconizado no exame post-mortem rotineiro. É importante lembrar que o exame postmortem deve ser realizado com uso de paramentação adequada (macacões, aventais, jalecos, botas plásticas, luvas, óculos de proteção e máscara cirúrgica) e em local restrito ao acesso público, livre de insetos, coberto, com fonte de água corrente, luz de boa qualidade (Smith, 1954; Silva e Vargas, 2005). Alguns equipamentos básicos são necessários para a realização desta técnica de análise post-mortem. A necropsia de aves pequenas pode ser monótona e, a menos que instrumentos de qualidade sejam utilizados, muita informação pode ser perdida. De acordo com o sugerido por Van Riper III e Van Riper (1980), o uso de instrumental oftálmico é altamente adaptável para esta prática, como tesouras de microdissecção de íris e fórceps de microdissecção. Outros equipamentos necessários incluem lâminas de vidro histológicas, lamínulas limpas, swabs estéreis e seringas, placas de Petri estéreis e fixadores para coleta de amostras teciduais, sacolas plásticas estéreis para congelamento de tecidos. A utilização das lâminas de vidro e lamínulas é de alto valor diagnóstico, uma vez que permitem a confecção de impressões citológicas que podem tanto ser lidas pelo médico veterinário em questão ou enviado para um laboratório de diagnóstico em patologia veterinária (Graham, 1987a).

Como o exame necessitará da realização de incisões no cadáver animal, faz-se necessário discutir previamente com o proprietário a técnica a ser utilizada, bem como obter a autorização do mesmo por escrito para a execução da necropsia no animal. O principal fator a ser definido para a realização de uma necropsia cosmética é limitar o número de incisões. Ao planejá-las, alguns pontos devem ser considerados, como o local e o tamanho das incisões, considerando sempre a acessibilidade aos órgãos.

$\mathrm{Na}$ técnica de necropsia cosmética, o mais indicado é que o cadáver do animal fique posicionado em decúbito dorsal, com os membros afastados para estabilizar a carcaça. A partir da região mentoniana até a região da cicatriz umbilical, deve ser feita uma incisão longitudinal no plano sagital mediano e uma incisão transversal na região dos últimos arcos costais, ambas na pele, (figura 1) com o uso de um instrumento cortante (tesoura ou bisturi, preferencialmente). 


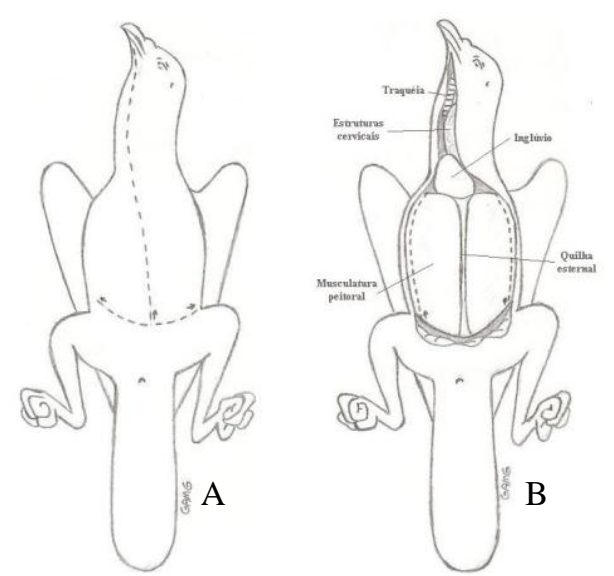

Figura 1 - A) Incisão primária transversal contornando a região das últimas costelas. $\mathrm{Na}$ sequência, realiza-se incisão longitudinal no plano sagital mediano a partir da região mentoniana até a região umbilical; B) Exposição dos órgãos cervicais; Rebate-se o conjunto musculatura peitoral-gradil costal incisando-se as articulações costocondrais.

A pele e a musculatura do abdômen devem ser dissecadas e rebatidas para permitir a exposição das estruturas cervicais e das musculaturas peitoral e abdominal, de modo a propiciar o acesso à cavidade celomática. Para tal, remove-se 0 conjunto musculatura peitoral-gradil costal (figura 1B) ao se osteotomizar a cintura torácica (coracóide e clavícula) e incisar as junções costocondrais. Antes da remoção completa do esterno, desloca-se o mesmo suavemente de forma a estender os sacos aéreos torácicos, analisa-se a aparência destes quanto à transparência, presença de líquidos, corpos estranhos, parasitas ou granulomas.

Com a cavidade celomática exposta deve ser observado se há ou não a existência de líquidos e, quando presentes devem ser analisados bioquimicamente e ter sua quantidade mensurada utilizando seringas, conchas e provetas de acordo com o porte da ave. Em seguida removem-se fígado e baço em um único bloco (figura $2 \mathrm{~A}$ ) e coração (figura 2A). Posteriormente realiza-se no duodeno uma ligadura dupla cranial ao pâncreas (figura 3A) e outra caudal à cloaca (figura 3B), permitindo assim a extração dos segmentos intestinais até a porção final do reto.

Subsequentemente devem ser removidos a traquéia, siringe, brônquios e pulmões ao se fazer a ressecção da traquéia nos seus primeiros anéis, seguida da dissecção craniocaudal das estruturas supracitadas (figura 4). Após a remoção do trato respiratório, libera-se a porção torácica do esôfago (figura 5). $\mathrm{Na}$ sequência, faz-se a desarticulação hióidea na região gular para a remoção do conjunto do aparelho laríngeo (língua, faringe, laringe e glote)(figura 6), de modo a permitir a remoção de todo 0 trato digestório superior (cavidade oral, esôfago, inglúvio, proventrículo e ventrículo) para posterior exame. Subsequentemente, os intestinos devem ser removidos (figura 7A).
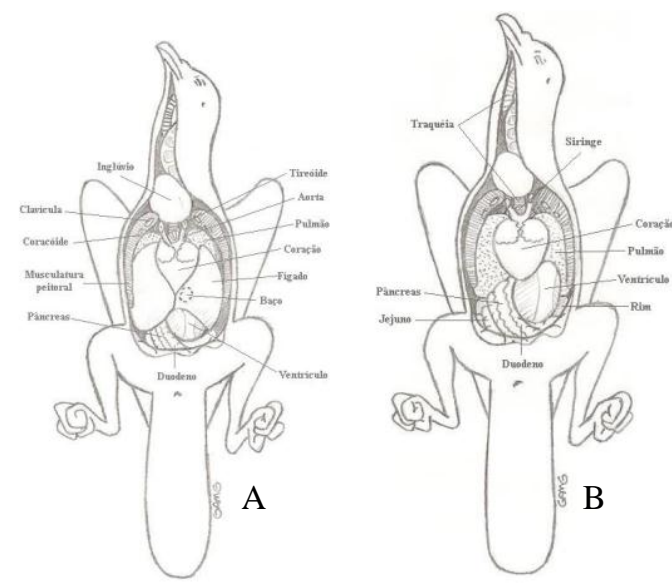

Figura 2 - A) Exposição dos órgãos celomáticos; o baço (linhas pontilhadas) encontra-se dorsalmente ao fígado e ventralmente ao ventrículo; retira-se o conjunto fígado-baço para permitir o acesso completo ao conjunto cardiorrespiratório e aparelho gástrico (proventrículo e ventrículo); B) Retirada do coração, com consequente acesso ao pulmão, esôfago torácico e ventrículo. 


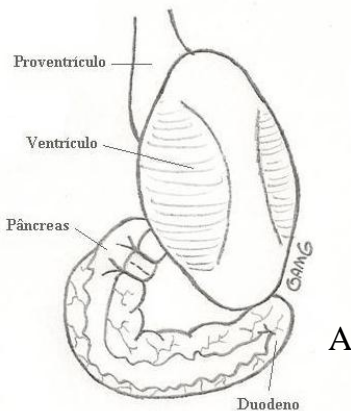

A

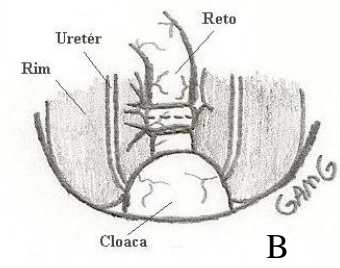

Figura 3 - A) Dupla ligadura na porção inicial do duodeno; B) Dupla ligadura retal. Realiza-se dupla ligadura na região retal e incide-se entre estas (linha pontilhada).

Com isso, consegue-se a exposição dos órgãos do trato urogenital e sua consequente remoção (figura 7B). Para remoção do oviduto faz-se uma ligadura dupla caudal, na porção uterina, perto a inserção com a cloaca e disseca-se o istmo do ovário. O ovário e testículos (no caso de macho), após localização, são removidos por simples dissecção para liberação da porção cranial dos rins.

Após a remoção dos órgãos celomáticos, um meio (algodão, estopa ou lã) embebido em solução de formol a $20 \%$ deve ser colocado dentro da carcaça para diminuir o extravasamento sanguíneo para o exterior do animal, e manter a estrutura corpórea o mais próximo possível do normal.

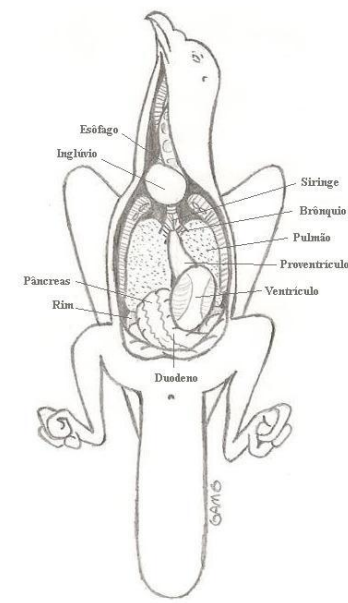

Figura 4 - Remoção do conjunto traquéiapulmão ao se realizar ressecção da traquéia na região dos primeiros anéis cartilaginosos (região gular) até a retirada do pulmão; consequentemente há a exposição do esôfago.
Os rins devem ser liberados do assoalho celomático juntamente com as glândulas adrenais. A própria conformação é suficiente para se discriminar entre rim direito e esquerdo.

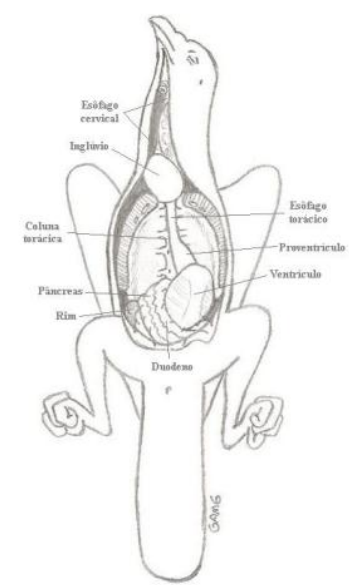

Figura 5 - Após a dissecção da região gular e da incisão entre a dupla ligadura na região duodenal, remove-se 0 conjunto laringeesôfago-estômago.

O exame do encéfalo não deve ser excluído, principalmente em casos de suspeita de neuropatias. Para remover o encéfalo da caixa craniana, faz-se uma incisão cutânea na base cervical da cabeça, na região atlantooccipital. Posteriormente, a pele e a musculatura são rebatidas facilitando assim a remoção da calota craniana (figura 8).

Os ossos parietais, temporais e occipital são osteotomizados com 0 auxílio de uma tesoura. É importante ter cuidado para não danificar o encéfalo. Após a remoção da calota craniana, com o auxílio da tesoura cortam-se as meninges, expondo assim cérebro e cerebelo. Ainda com a utilização de tesouras, os nervos cranianos e o quiasma óptico são seccionados para facilitar a remoção do encéfalo. Devido às características anatômicas, não é possível remover a medula espinhal na necropsia cosmética. 


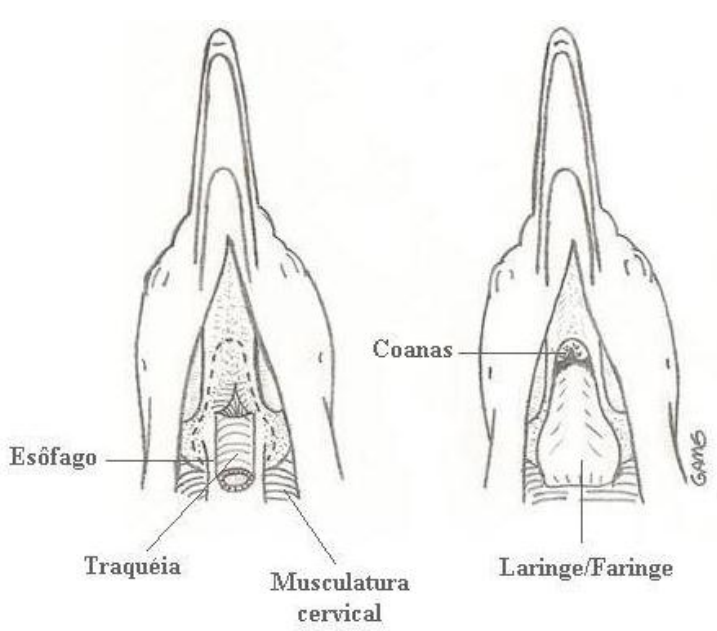

Figura 6 - Dissecção da região gular para remoção do conjunto língua-laringe-esôfago (seguir trajeto da linha pontilhada para realização da incisão e correta remoção); com isso, expõem-se as coanas.

Antes de fazer as suturas finais, reposiciona-se a estrutura peitoral, suturando $o$ gradil costal e a musculatura regional (figura 9A). Após a retirada dos órgãos celomáticos para análise, as incisões feitas no cadáver do animal devem ser suturadas (figura 9B) e as manchas de sangue e outros fluidos corpóreos limpos. $\mathrm{Na}$ região cefálica, a calota craniana deve ser reposicionada em seu local original e, na seqüência, a pele que recobre a área deve ser suturada (figura 8).
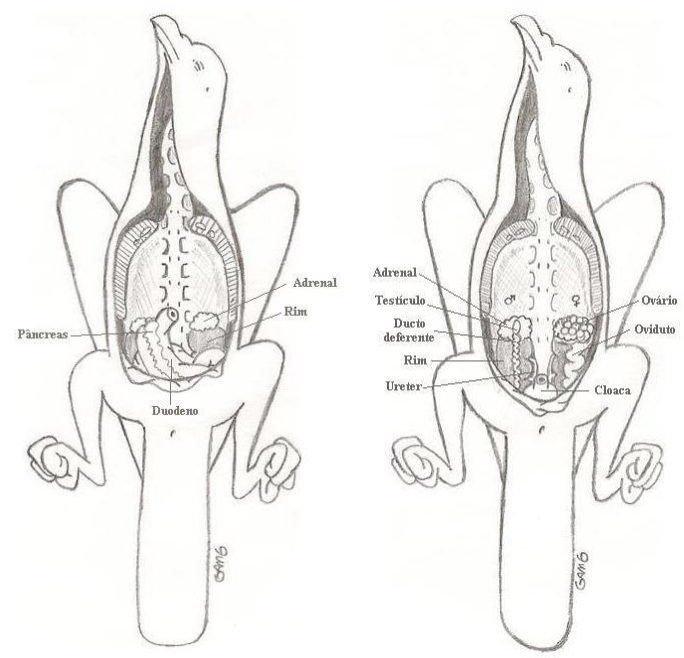

Figura 7 - A) Remoção dos intestinos. Após remoção do conjunto esôfago-gástrico e realização da incisão na região retal entre a dupla ligadura, removem-se os intestinos para exposição do trato genitourinário; B) Remoção do trato genitourinário. Removidos os intestinos, removem-se primeiramente as gônadas e, subsequentemente, adrenais e rins. Representação esquemática para ambos os sexos; antímero direito - macho; antímero esquerdo - fêmea.

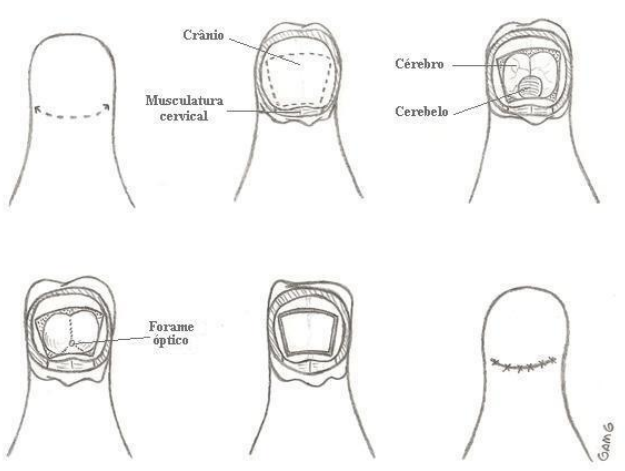

Figura 8 - Remoção do encéfalo. Após rebater a pele na região atlantooccipital, osteotomiza-se o osso occipital para exposição do cérebro e cerebelo. Com auxílio de pinça e tesoura, incisam-se as meninges (separando-as do encéfalo) e suspende-se $o$ encéfalo para permitir o acesso ao quiasma óptico e sua incisão para liberação do conjunto. Após a remoção, recoloca-se a calota craniana e sutura-se a pele da região.

Amostras de todos os órgãos devem ser fixadas em solução de formol a $10 \%$, para posterior realização de exame histopatológico. A melhor zona para a coleta é a zona de transição entre a lesão e o tecido normal adjacente (Pires, 2002). Deve-se evitar a coleta de amostras muito pequenas ou fragmentadas, com 0 risco de se perderem na manipulação ou não conterem material suficiente para 0 processamento e análise para a emissão de um diagnóstico (Pires, 2002), sugerindo-se amostras com dimensão aproximada de no máximo de $0,5 \mathrm{~cm} \times 0,5 \mathrm{~cm} \times 0,5 \mathrm{~cm}$ para melhor penetração do formol e conseqüente fixação de melhor qualidade (Graham, 1987b). É importante armazenar as amostras em frasco de boca larga para melhor manuseio por parte do patologista veterinário (Silva e Vargas, 2005). 


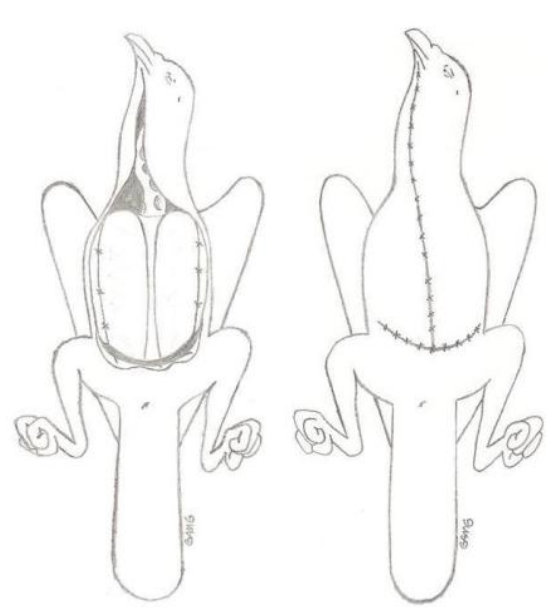

Figura 9 - A) Após a completa evisceração reposiciona-se o gradil costal, suturando-o à musculatura peitoral; B) Após a recolocação do gradil costal faz-se a dermorrafia no plano sagital mediano e na incisão transversal previamente realizadas, com posterior limpeza externa do cadáver.

Se necessário, coletam-se amostras para exames microbiológicos ou toxicológicos se a anamnese ou os achados clínicos indicarem alguma doença infecciosa ou intoxicação (Benbrook, 1954; Peixoto e Barros, 1998; Rae, 2003; Silva e Vargas, 2005). Para amostras de interesse toxicológico, coletam-se amostras de rim, fígado, cada um de 50 a $100 \mathrm{~g}$ (quando em espécies grandes), e todo o conteúdo gástrico, estocando-os em sacos plásticos e mantendo sob refrigeração para envio aos centros de análise competentes. Quando necessária a colheita de sangue (devendo ser colhidos de $1 \mathrm{a} 4 \mathrm{~mL}$ ) pode ser realizada com armazenamento em tubos sem anticoagulantes, exceto para a análise de chumbo para a qual o sangue deve ser armazenado em tubos contendo heparina ou EDTA (Graham, 1987c; Oliveira et al., 2002). A coleta de sangue post-mortem pode providenciar informações extremamente importantes e deve ser a rotina, e não a exceção nas necropsias aviárias. Mesmo se a carcaça tiver sido congelada e descongelada, ainda é correto coletar sangue do coração. A agulha para colheita deve ser inserida através do ventrículo direito em direção ao átrio direito para obter a amostra. (Graham, 1987c). Se o local tiver sido contaminado antes da colheita da amostra, uma espátula deve ser aquecida e sua superfície deve ser pressionada contra a região de inserção da agulha. A amostra colhida deve ser tratada de forma semelhante a uma adquirida ante-mortem. Esfregaços sanguíneos podem ser corados através da coloração de Wright e Giemsa. A evidência de bacteremia pode ser revelada através da coloração de Gram. Tais amostras podem ser alocadas em sacos plásticos ou tubos de coleta próprios com meios de cultivo adequados, substâncias anticoagulantes etc, para posterior resfriamento (Smith, 1954; Baker e Alvarado, 1969; Niwayama, 1996; Silva e Vargas, 2005).

\section{CONCLUSÃO}

Com o recente avanço das técnicas de diagnóstico ante-mortem, muitos profissionais têm negligenciado a execução do exame post-mortem no animal $^{11}$. Entretanto, essa prática ainda se constitui como uma ferramenta importantíssima de diagnóstico e proporciona uma melhor relação entre os sinais clínicos apresentados por um animal em vida com as lesões e achados macroscópicos observados após a morte, validando os achados ante-mortem e muitas vezes encontrando outros que não foram aparentes durante a vida (Smith, 1954; Baker e Alvarado, 1969; Silva e Vargas, 2005).

A necropsia convencional tem menor aceitação junto aos proprietários por não manter o aspecto externo de seus animais e desfigurar o cadáver. A técnica de necropsia cosmética, por sua vez, aumenta a aceitação do procedimento pelos proprietários ao seguir o mesmo princípio das autopsias humanas não-desfigurativas, que 
simultaneamente possibilitam a realização do exame post-mortem e que ao final de sua execução o cadáver esteja mais próximo possível de seu estado externo original (Baker e Alvarado, 1969). Isto confere as condições ideais para avaliação da conduta médica e terapêutica ao compará-las com os achados de necropsia, prática fundamental na instituição do diagnóstico, aprendizado e controle da qualidade da atividade do médico veterinário. É importante ressaltar que a necropsia cosmética baseia-se na preservação de cadáveres, um fato que torna a realização desta técnica interessante também nos animais silvestres ou selvagens e também com interesses científicos e educacionais (Woboser, 1996; Munro, 1998; Stround, 1998), visto que atualmente clínicos têm se mostrado cada vez mais interessados na medicina de animais de companhia exóticos (Kerwick et al., 2008).

Salienta-se também que a necropsia cosmética é uma técnica de maior custo do que a convencional visto que oferece dificuldades de execução, necessitando de tempo maior para realização das incisões, retirada dos órgãos e dermorrafias.

Em razão das dificuldades expostas, considera-se a necessidade de pessoal especializado para sua realização. Neste contexto, é ressaltada a importância da supervisão e auxílio do patologista, uma figura indispensável para que se consiga uma análise acurada da causa da morte (Baker e Alvarado, 1969), sendo ainda mais importante a figura do patologista veterinário com experiência na avaliação de aves ou de um ornitopatologista.

\section{REFERÊNCIAS}

BROWN, S. The human-animal bond and self psychology: toward a new understanding. Society and Animals, v.12, n.1, p.67-86, 2004.
LORENZ, K. E o homem encontrou o cão... Relógio D’Água editores, 258p., 1997.

ALLEN, K.M. Coping with life changes \& transitions: the role of pets. Interactions, v.13, n. 3, p.5-6, 8-10, 1995.

SILVA, J.C.P. VARGAS, M.I.V. Necropsia em Medicina Veterinária. 3aㅡ edição. Editora UFV. 36p. 2005.

HULL, M.J.; NAZARIAN, R.M.; WHEELER, A.E.; BLACK-SCHAFFER, W.S.; MARK, E.J. Resident physician opinions on autopsy importance and procurement. Human Pathology, v.38, n.2, p. 342-350. 2007.

BURTON, J.L.; UNDERWOOD, J. Clinical, educational and epidemiological value of autopsy. Lancet, v.369, n.9571, p.1471-1480. 2007.

CARVALHO, H.V. Anatomia patológica criminal. Arquivos da Polícia Civil, v.4, n. 2, p.488, 1942.

VAN RIPER III, C.; VAN RIPER, S.G. A necropsy procedure for sampling disease in wild birds. Condor, v.82, p.85-98. 1980.

SMITH, H. General principles of necropsy procedures. In: JONES, T.C.; GLEISER, C.A. Veterinary Necropsy Procedures. Philadelphia, PA: B. Lippincot Company. p. 3-9. 1954.

PIRES, M.A. Recolha e envio de material para análise histopatológica. Proceedings of the Veterinary Sciences Congress, SPCV, Oeiras, p.229-238, 2002.

BENBROOK, E.A. The importance of necropsy. In: JONES, T.C.; GLEISER, C.A. Veterinary Necropsy Procedures. Philadelphia, PA: B. Lippincot Company. p. 1-2. 1954.

PEIXOTO, P.V.; BARROS, C.S.L. A importância da necropsia em medicina veterinária. Pesquisa Veterinária Brasileira v.18, n.3, p.3-4, 1998.

OLIVEIRA, P.; OLIVEIRA, J.; COLAÇO, A. Recolha e envio de amostras biológicas para o diagnóstico de intoxicações em carnívoros domésticos. Revista Portuguesa de Ciências Veterinárias, v. 97, n. 544, p. 161-169. 2002.

GRAHAM, D.L. Impression smears aid diagnosis. Association of Avian Veterinarians, v.1, n.2, p. 67.1987 a. 
GRAHAM, D.L. Miscellaneous necropsy tips. Association of Avian Veterinarians, v.1, n.2, p. $67.1987 \mathrm{~b}$.

RAE, M.A. Practical avian necropsy. Seminars in Avian and Exotic Pet Medicine, v.12, n.2, p. 62-70. 2003.

GRAHAM, D.L. Post mortem blood evaluation. Association of Avian Veterinarians, v.1, n.2, p. $67.1987 \mathrm{c}$.

BAKER, R.D; ALVARADO, D.M. Tecnicas de necropsia. México: Talleres de Edimex. 175 p. 1969.

NIWAYAMA, G. Postmortem blood microbiology using sterile autopsy technique. The Tohoku Journal of Experimental Medicine. v. 105, n. 3, p. 247-256. 1971.

WOBOSER, G. Forensic (medico-legal) necropsy of wildlife. Journal of Wildlife Diseases, v.32, n. 2, p. 240-249. 1996.

MUNRO, R. Forensic necropsy. Seminars in Avian and Exotic Pet Medicine, v. 7, n. 4, p. 201-209. 1998.

STROUD, R.K. Wildlife forensics and the Veterinary practioner Seminars in Avian and Exotic Pet Medicine; v.7, n. 4, p. 182-192. 1998.

KERWICK, C.M.; MEERS, J.; PHILLIPS, C.J.C. Training Veterinary personnel for effective identification and diagnosis of exotic animal diseases. Journal of Veterinary Medical

Education, v. 35, n. 2, p. 255-261. 2008. 